ating power, superadded, ss it were, upon the normal energies of the system, or taking their place, such as we find to be the character of malignant disease; nor, on the other hand, is it identical with the effusions of blood-constituents which result from an exaltation of the normal energies, and continue in possession of their vitality, by which they are susceptible of organisation. This we do not see in tubercular deposit, which must be viewed as bearing to the diathesis giving rise to it, very nearly the same relation as, to use the strongest comparison that suggests itself to us, calculus in the bladder bears to the calculous diathesis to which it is due. There is, unfortunately, no such emunctory for the effete protein compounds, as there is for the excess of saline constituents of the blood; or tubercle might accumulate as the latter do, at a given point, and the product be removed by operative proceedings, or by chemical solution. The lungs and the skin have this duty to perform; but I need not stop to point out to you why we have not yet succeeded in destroying the tubercular product in the former, and removing it from them, by direct applications. I do not myself despair of a remedy being discovered which, in a gaseous form, may be conveyed to the deposit in the lungs, and, by dissolving it, enable the patient to expectorate it; but this would only affect a single organ. The cachexia leading to the local product will ever remain the real malady to deal with, so that we may anticipate its local effects.

The changes which take place in the deposit itself, and which have been the source of much discussion, and of some very wild speculations, are, as I have already ohserved, closely allied to what we see taking place out of the human body in inorganic substances. They seem to follow the laws regulating crystallization and chemical decomposition rather than those of vital action.

The earliest form in which tubercle presents itself to the eye is that of a faintly granular blastema, in which we are only just able to trace a tendency to aggregation into circular forms. An instance of this is given in the microscopic view of the miliary tubercle represented in drawing No. $91 a$, which was taken from a case of acute tuberculosis occurring in a patient of Dr. Markham's, secondary to rheumatic disease of the heart, and central softening of the brain. Here, as elsewhere, while the process of deposition continued, the vicinity of the tubercular matter was surrounded by exudation corpuscles, with or without an enveloping wall. The next form which we find tubercle presenting is that of more definite corpuscles; they offer an oval form, with a more or less sharp outline, and a granular surface. These corpuscles are surrounded by the granular blastema before mentioned, which now becomes more definitely marked, and by and bye appears to eliminate oil-globules in a greater or less quantity. The tubercular corpuscle does not present a nucleus as its normal constituent ; it is, in fact, regarded by some, among whom I may be allowed to mention your excellent secretary $D r . H$. Jones, as itself a nucleus. We occasionally find cells with nuclei in tubercular matter, as you will observe in several of the drawings which I send round, but I am inclined to think that they are generally, if not always, derived from the normal tissues of the organs in which the deposit has taken place. In many cases the corpuscles offer no distinct cell-wall, but appear merely to be an aggregation of the granular blastema; and at all times the envelope presents but a faint outline, compared to the sharp and well-marked margin which we discover in the cancer or epithelium cell. In examining tubercle taken from different organs, we must never forget that an admixture of the cells and corpuscles belonging to the healthy tissues may take place, which, at first sight, gives an appearance to the microscopic field different from that described. Another source of difficulty, also, consists in the admixture of the products of secondary inflammation, which is often excited by the tubercle acting as a foreign body. In the former case, our knowledge of the healthy tissues must guide us; in the latter, we must carefully discriminate blood-corpuscles, pus, or debris of the tissues, from the tubercular deposit. In the instance of tuberculated kidney which I submit, you will see that renal cells are mixed up with the true tubercular matter; in the glands the normal corpuscles often closely resemble the tubercular, and some care is necessary to distinguish the two. The characters which I have laid down will generally suffice to determine the question; and we may also bear in mind, that while in normal components there is generally more definiteness of outline and uniformity of shape and size, the elements of morbid products are characterised by an absence of that typical regularity. The dimension of the tubercular corpuscle generally fluctuates from one to three five-thousandths of an inch.

A term has of late been brought into rogue by the authority of great names, to which, before concluding this brief sketch, it is necessary that I should allude, as the subject to which it refers is closely associated with tubercular disease. I refer to fibrinous deposits. Many of the cases which are thus denominated present no differences perceptible, either to the naked eye or under the microscope, by which we can distinguish the product from tubercle; and in such it is scarcely in accordance with sound induction to assume a different disease, until we are able to domonstrate a distinct primary lesion in the blood. It is not my intention to enter fully into this very important question at present, because I should fear to exceed the limits of your patience; but I wish to point out that, while there is a wide distinction between the two forms of disease in their well marked characters, they occasionally merge into one another, and are associated together. In drawing 104, $I$ have represented the most marked instance of a combination of tubercle and fibrine which I have met with. You perceive that the characters of each are maintained as shown in the micruscopic view; while, at the same time, the naked eye appearance of the morbid product corresponds with those of ordinary tubercle. When we remember the close approach between the elementary composition of fibrine and albumen, it is only surprising that the morbid products which are formed from them should present on the whole the broad distinctions that we recognize. Here, as elsewhere, we must look further back than to the mere local deposit: the primary cause resides in the perverted impulse given to the system; that impulse itself we shall never be able to seize with physical means, but we may hope to obtain an insight, a sensual appreciation of its manifestations at an earlier period than has yet been vouchsafed to us. When we do this, we may hope to be more successful in applying our curative agents ; till then we shall see but as through a glass darkly, and our steps will be, like those of the infant learning to walk, insecure and infirm.

I cannot take my leave of you without apologising for attempting to touch upon a subject of such vast importance as that of tubercle in so cursory a manner. No one is more conscious than I am myself of the very imperfect manner in which the little that has been said has been brought before you. And though I may have failed to suggest anything which your own observations and researches have not already made out, I may succeed in eliciting the observations of other inquirers into this field of pathology, which will deserve the attention of the learned members of this Society.

May 1833.

\section{ON REVACCINATION.}

\section{By J. A. HINGESTON, Esq.}

Or those who hare been once properly vaccinated, an indeterminate number become again susceptible of raccination at a subsequent but indeterminate period of their lives. It is said that this susceptibility never occurs within six months after an effective primary vaccination; and this interval of protection has been extended to seren or even ten years ; but there are no proofs to warrant our implicit confidence in this assertion. The scar of a genuine vesicle is no evidence of insusceptibility ; for those without a scar will remain insusceptible both of the small-pox and revaccination all their days; while others, with a scar of 
normal character, will take the amall-pox or revaccination, notwithstanding this apparent testimony in their favour, and contrary to our most sanguine cxpectations of their security. Some vaccinators say, that about half the number of those vaccinated are susceptible of a revaccination; but this computation, though it may depend on statistical calculations, gives no assurance of its positive accuracy; for, out of this susceptible half, there may be justly reckoned a great many who have been imperfectly vaccinated at the beginning, and therefore have never been thoroughly protected at any moment from the first.

The question has arisen, Whether the protective agency of raccination docs not wear out with age? Perhaps this is the most popular notion entertained upon the subject; but it is, nevertheless, an entirely gratuitous one. There is nothing to prove that this is the case. It has been proposed to repeat vaccination every seven years in each individual; but this, like the foregoing opinion, is taken for granted, and nothing actually certain is ever preteuded to be advanced in support of it. To adopt such a measure from some vague sense of precaution, is as unphilosophic as it is likely to prove illusire.

If one half of the vaccinated are safe, as some suppose, what signs are there to indicate the particular kind of constitution comprehended within this fortunate moiety? It is evident they exhibit no premonitory signs by which we may recognize them. It is mere guess work. If, as it is generally admitted, a primary genuine vaccination do occasionally prove unprotective, what reason have we for concluding that a secondary genuine vaccination should prove more protective than the first? There is neither reason nor evidence to enable us to form any satisfactory judgment respecting it. And, even supposing the patient to be unprotected by the first, we have no test to assure us that he will not be liable to take the small-pox, in spite of his remaining insusceptible to the virus of a secondary vaccination. The value of a negative proof is very precarious.

The varieties and degrees of susceptibilities and insusceptibilities constitute a problem which no one has hitherto attempted to solve. Our information respecting vaccination in general is scanty enough, and practical writers have not thought it worth their while to bestow more than some passing thoughts upon it. The result has been, that theories have been broached, and allowed to pass current without challenge, inquiry, or remark; opinions have been mistaken for facts; and, excepting on a few rare points (such as the variolation of the cow), vaccination is now almost just where it was upon its first discovery.

A foreign writer, of the name of Wendt, recounts, that out of 275 revaccinated in the Danish army, more than half succeeded. But vaccination has succeeded, it is declared, in persons already deeply pitted with the small-pox, to the amount of one half, which is about the same proportion. Jenner himself at last perceived and owned, that the susceptibility to cow-pox is renewed in some constitutionsan admission which only shows that vaccination, like everything else on the earth, is neither universal nor infallible. Our just confidence in a remedy is weakened by overrating its value. Of the deaths from small-pox in some of the largest cities and towns of Great Britain, four-fifths occur in the first five years of life. If this account be authentic, then these children were either not vaccinated at all, or clse, if vaccinated, they took the small-pox at the precise age when vaccination ought to be the most protective.

The question of revaccination is embarrassed on all sides. In times of danger from infection of the small-pox, it is unquestionably proper. For the most part, a genuine scar is the sign and seal of protection; and most raccinators will feel confident that, in such a case, revaccination will in all probability produce nothing more than a spurious pock, running its course in five days; or that, if small-pox supervene, it will be only a mild form of it, terminating favourably in a week, and seldom proceeding so far as the fourteenth day. Should the attack, however, turn out a severe one, the medical man will be inclined to suspect the normal character of the primary vaccination; for he has a firm conviction, or consciousness, derived from his own experience, that a genuine vaccination, carefully watched and approved of genuine vaccination, care nerer deceires him. It is, in his estimation, proof impregnable against the small-pox infection, and of strength sufficient to resist the specific virus of revaccination. We may appeal to those who have been attentive observers of what has transpired within their own sphere of practice, and ask them whether this declaration does not express the unshaken conclusion of their minds? Testimony of this sort is of no trifling weight, and supersedes the nicest arguments which can be opposed to it. In a court of law, it would be decisive. Many a doubtful point, however, would be cleared up and settled by the returns of extensive statistical reports on vaccination, such as those of the Registrar-General's respecting births, deaths, etc.; and an arrangement of this kind might be provided for in a new Vaccination Act.

The proper age for vaccinating has been determined by necessity rather than by choice. The usual time is about the third month, nor does there seem to be any good reason against it. At this period, the pock usually succeeds very well, without interfering with dentition, weaning, or the change of dress, which is generally made lighter. towards the eighth or ninth month. Indeed, there is no $t$ me when the nursing and warmth are more carefully attended to than at this period, nor when the infant is more susceptible and less irritable than then. About this time, also, healthy children are plump, and they sleep a good deal, both of which are farourable conditions for vaccinating. The spring and autumn are the best seasons for obtaining fully developed vesicles. The winter checks the action of the skin, and the summer overheats and exhausts the surface. The one hurries on, while the other delays the progress of the pock. It is best to postpone the vaccination altogether in very cold weather, and to wait for a more congenial temperature.

Dentition by no means hinders the virus from taking effect; and every vaccinator is aware of vesicles being preduced as perfect, and as much approved of, at this time as at any other; only the liability to secondary eruptions is greater, and the constitutional powers are engaged in the formation of the tecth, which is an important process, making a great call upon the strength, disturbing the regularity of the nervous centres, and occupying the chief activity of the system almost exclusively in its own operations. On this account, it has been recommended to postpone vaccinating until after the formation of the first teeth, or at least until after the expiration of the first twelve months. Except in some particular cases, there does not seem to be any good ground for giving way entirely to such a scruple.

No one would ever think of vaccinating during the existence of feverishness, sleeplessness, diarrhœa, catarrh, etc., in children ; nor in adults during menstruation, an attack of indigestion, jaundice, excessive fatiguc, care, grief, or any other accidental circumstance interfering with the goneral health.

The fourth month used to be the age at which the old inoculation was practised, and the child's health was prepared for its reception. Under the most favourable conditions, it was not free from risk; for sometimes the smallpox eruption came out over the whole body, and occasionally children died in consequence of it. During the incubation of the small-pox, that is to say, between the moment of infection and the appearance of the eruption, vaccination may be attempted. Its success will depend on its being performed nearer the moment of infection than that of the eruption. Some say that, if vaccination be effected within six days from that of the infection, the vesicle will arise, and anticipate or intercept the appearance of the smallpox. Others affirm that, even though vaccination should be attempted as early as the moment of infection itself, yet it will not do more than modify the character of the smallpox; while others, again, declare that, if vaccination take place consentaneously with the small-pox eruption, then the small-pox eruption will proceed pari passe with the vaccine vesicle. Nay, it is even asserted, that a confluent small-pox 
will proceed along with a genuine vaccine vesicle. It is evident that these are abstruse points, almost beyond the reach of a private individual's experience. Nothing but extensive reports, spread over the space of several successive years, could furnish us with anything like positive data for working by. In the case of imminent exposure to infection, we are forced to vaccinate without delay, and trust to chance for its succeeding.

It is stated that, when a child has been raccinated and inoculated at the same time, and almost on the same part, so as to allow of the vesicles uniting, the virus taken from this compound pock will produce either cow-pox or smallpox, no one can foretell which; and that inoculation with vaccine and variolous virus mixed will give rise either to the one or the other of the two diseases indiscriminately. These curiosities in pathology scarcely bear upon practice; perhaps they may be adduced in proof of the identity of the two affections; but their importance does not extend much beyond the limits of their own intrinsic value. Like many other phenomena, they begin and end in themselves, because we are ignorant of their exact relations.

As the greater number of children who die from smallpox, dic between their birth and the second month of their existence, it is advisable to vaccinate the poor as early as possible. Their means do not enable them to isolate themselves, and live apart from the sources of contagion and infection, like the rich. Moreover, they are disposed to be negligent in this as in all other matters; and it is difficult to make them see the importance of being vaccinated at all, or, if raccinated, of bringing their children to be inspected on the proper days throughout the progress of the pock. The consequence is, that, when seized with the small-pox in after life, they are said to have been vaccinated in their infancy; whereas the vaccinator had never been allowed to watch the vesicle, and therefore could never vouch for its protective quality. When I resided in London, I vaccinated many poor children; but, owing to the necessities or ignorance of this class of people, the vaccinations were desultory, and a great number departed or disappeared, without rendering any account of themselves. In instances like these, the appearance of small-pox after vaccination cannot be surprising. The fault does not rest with the medical practitioner, for he cannot control the caprices of the public. The wealthier classes contract small-pox through the indiscretion of their domestics, who visit infected places, and bring it back with them.

A child, on the eve of sickening for measles, etc., may happen to be vaccinated, and in this case the vaccination may not appear, but lie dormant until after the measles have passed away, and then come forth, and pass through its stages with apparent regularity. Every vaccinator is, I believe, aware of a genuine vaccination being delayed for two, more, or several days ; and in some seasons the best virus fails in taking effect, no one knows why. The insusceptibility to vaccine is more frequently to be imputed to defective lymph, than to any constitutional peculiarity in the patient. Good lymph seldom fails in taking effect.

Hooping cough was at one time supposed to be cured by raccination, but subsequent experience has not confirmed this theory. Some have considered that vaccination has cured eruptive diseases, while others affirm that it has produced or aggravated them. These notions most likely turn upon the old difficulty of distinguishing between the sequence and the consequence of events.

The secondary lichen after vaccination is urged as a strong reason against its practice. The virus is supposed to have conveyed something prejudicial into the blood, and thereby provoked scrofula, etc. But it is not easy to determine what is the immediate and exciting cause of scrofula, which may be attributed to many other causes besides vaccination. Anything may awaken it from its latent state, and render it active for a shorter or longer period, if not for the remainder of life. Be this as it may, the constitutional ailments which are said to follow upon vaccination, may be avoided by the use of purgatives (hydr. c. creta) proportioned to the patient's age and strength. All erup- tive diseases require this treatment at their close, and the vaccine pock among the rest. In scarlet ferer, the train of awkward symptoms which manifest themselves in the throat and kidneys may be remored by purgatives, exhibited for the space of three or four weeks during convalescence. It is the same with measles, in which the lippitudo and diarrhoea that threaten to supervene may be averted by the same means. It is especially the case with small-pox, which requires repeated laxatives on its cessation. Variolous inoculation, and its congener vaccination, call for the same treatment. The cachexy following eruptive diseases, fevers, inflammations, etc., may be traced up to the neglect of this wholesome practice; and the eruptions spoken of as occurring after vaccination may be ascribed to the same omission.

Lichen is apparently an inflammation of the nervous structure of the skin-a true hyperasthesia, and the eruption is but an accident; for in many cases of prurigo there is no eruption at all. In plethoric subjects, salines, laxatives, and antimonials, together with the use of warm bathing, are the proper remedies ; but in cold constitutions, and debilitated persons, the opposite treatment is called for, and stimulating the skin is the best practice. It is analogous to that asthenic conjunctivitis which is curable by stimulating lotions (argenti nitras), but which is aggravated by depletion. The prurigo senilis, so rexatious and obstinate in advanced life, yields to the popular remedy of beef-brine, with saltpetre dissolved in it. These few observations, respecting the nature and treatment of lichen, may not be out of place on the present occasion.

The foregoing account is not a very satisfactory one; and it is for this reason that $I$ have reserved it to the last, and been at the pains of drawing it up thus succinctly. It is surprising how many loose opinions are afloat upon vaccination, and pass current for truth among the public. But if we deduct the few facts that are really known, we shall find the absolute data are only three: viz., 1 , the source of genuine lymph, i. e., the cow ; 2 , the natural history of the vesicle; and 3 , its power of protection, when rightly performed. Other points, of not less vital importance, meet us at every step; but they are enveloped in doubt, elude our grasp, and escape from sight. They remain as subjects of investigation for the philosophic student; and it only requires a school, regularly organized, appointed, and authenticated, in order to bring them within the focus of enlightened research. The cow might be variolated from time to time, so as to procure a genuine supply of fresh lymph whenever it is called for; vaccine wards might be opened ; vaccinators, as well as a lecturer on vaccine, might be officially installed; and pupils, accurately educated, might be sent forth, capable of discerning between a true or false pock, as well as skilful in the art of keeping up a constant succession of approved vesicles. At present we have nothing of the sort. The legislature may shift the scenery for us; but the chief and real actors in the drama must be those who preside over the destinies of the medical profession as its preceptors, guides, and friends.

\footnotetext{
Brighton, Mlay 1853.
}

FRFE WHI.. "There is a cert ain difficulty in reconciling a free will with a supcrintending and guiding l'rovidence. But take an analogous instance, where a man stands in the relation of a guiding providence to an animal. 'The horse has a will. Breaking in, the harness, the reins, the whin, the spur, all are proofs of the animal's will, and of the necessity of its training. The horse is harnessed to a velicle, and guided by a man. So far as the animal's free will is exerted in the direction the driver chonses, the animal fulfils his purpose. Let him exert that will in opposition to his ruler, and he is driven by the lash to submision. So with man. He has a self-detenuining power, and as long as he submits that will to the oliedience of his reason, enlightened by the Divine light, he is fultilling his duty; he is working with and by his Maker; his will is in harmony with the Divine will. But deprive it of its freedom, and it becomes instinct ; responsibility ceases, and the foundation of all freedom -law and self-culture-is destroyed."-Fvening Thoughts. By a Physician. P. 20. Second edition. London: 1853. 